\title{
Physicochemical Properties and Sensory Characteristics of Semi-dried Pork Jerky with Rice Bran Fiber
}

\author{
Tae-Hyun Kim¹, Yun-Sang Choi², Ji-Hun Choi², Doo-Jeong Han¹, Hack-Youn Kim¹, Mi-Ai Lee ${ }^{1,3}$, \\ So-Yeon Shim ${ }^{1}$, Hyun-Dong Paik ${ }^{1}$, and Cheon-Jei Kim ${ }^{1,2 *}$ \\ ${ }^{1}$ Department of Food science and Biotechnology of Animal Resources, Konkuk University, Seoul 143-701, Korea \\ ${ }^{2}$ Research Institute for Meat Science and Culture, Konkuk University, Seoul 143-701, Korea \\ ${ }^{3}$ World Institute of Kimchi, An Annex of Korea Food Research Institute, Seongnam 463-746, Korea
}

\begin{abstract}
This study evaluated the effects of rice bran fiber (RBF) on the quality of semi-dried pork jerky (SDPJ). SDPJ was supplemented with RBF at levels of 0 (control), 1,2, and 3\%. The addition of RBF at various levels affected the composition of SDPJ except for the fat content $(p>0.05)$. The addition of RBF at a level higher than $2 \%$ increased the protein and ash contents of SDPJ $(p<0.05)$. The addition of RBF at various levels also affected the physiochemical properties of SDPJ $(p<0.05)$ except for water activity $(p>0.05)$. Increased level of RBF increased the $\mathrm{pH}$. The rancidity of SDPJ was increased $(p<0.05)$ regardless of the RBF level, whereas the metmyoglobin content (\%) of SDPJ was increased at a level higher than $2 \%$. Increased level of RBF decreased the shear force $(p<0.05)$ and the increased processing yield of SDPJ $(p<0.05)$. Jerky made with $2 \%$ RBF scored highest for sensory properties, including color, tenderness, juiciness, and overall acceptability $(p<0.05)$. These results indicate that SDPJ containing $2 \%$ RBF had the most acceptable quality characteristics, but further study is required to reduce the rancidity induced by the addition of RBF.
\end{abstract}

Key words: semi-dried jerky, dietary fiber, rice bran fiber, shear force, sensory property

\section{Introduction}

Jerky is a traditional meat product that is preserved by curing and drying, which reduces the water activity and controls microbial survival and growth (Han et al., 2007). Because of its easy preparation, light weight, high nutrient content, and stability without refrigeration, jerky is in high demand as a snack food and widely available to consumers (Choi et al., 2008a). In jerky products, texture is one of the most important sensory attributes (Han et al., 2007). Textural properties are very important to consumers, and can be used to assess quality (Han et al., 2007). Studies attempting to improve jerky texture have addressed the treatment of raw meat (Choi et al., 2008b), drying temperature (Han et al., 2007), drying time (Kim et al., 2006), salt addition (Lee et al., 2004), marination conditions (Choi et al., 2006), and packaging methods (Choi et al., 2007a). Attempts have also been made to upgrade the

*Corresponding author: Cheon-Jei Kim, Department of Food Science and Biotechnology of Animal Resources, Konkuk University, Seoul 143-701, Korea. Tel: 82-2-450-3684; Fax: 82-2-444-6695, E-mail: kimcj@konkuk.ac.kr texture of meat products in order to supplement them with functional foods.

Among functional foods, dietary fiber plays an important role in the human diet, not only for its nutritional properties but also for functional and technological properties (Choi et al., 2008b, 2010). Moreover, dietary fiber can be added to meat products to enhance the cooking yield due to its water and fat binding properties, and to improve the texture (Choi et al., 2010, Cofrades et al., 2000; Thebaudin et al., 1997). Many forms of dietary fiber have been used in the formulation of meat products such as patties (Piñero et al., 2008), sausages (FernándezGinés et al., 2004; García et al., 2002), and meat balls (Yilmaz and Daglioglu, 2003). Sources of dietary fiber used for this purpose include wheat bran (Yilmaz, 2005), oat bran (Yilmaz and Daglioglu, 2003), lemon albedo (Fernández-Ginés et al., 2004), and orange fiber (Fernández-López et al., 2008). There are few studies, however, addressing the use of rice bran in meat products.

Rice is the staple food of Koreans, so annually huge amounts of rice bran are produced as an agricultural byproduct from rice milling. Rice bran has high nutritional value in its content of lipids, proteins, minerals, vitamin 
B, and dietary fiber (Choi et al., 2009; Kim et al., 2001), but the utilization of rice bran is limited to the production of bran oil and animal feed. Because rice bran has considerable quantities of lipid, it does not store well and thus its quality deteriorates very rapidly by lipid oxidation (Choi et al., 2008b). The resulting development of offflavor and high free fatty acid content are due to the presence of enzymes such as lipase. Chotimarkorn and Silalai (2008) reported that the removal of lipids from dietary fiber reduces the rate of deterioration, thus dietary fiber from rice bran has potential for use in various foods. Recently, the utilization of rice bran has been used in dough and biscuit (Sudha et al., 2007), pork meatball (Huang et al., 2005), pork patties (Choi et al., 2008b), and emulsion-type sausage (Choi et al., 2008a). However, there are no researches to evaluate the suitability of rice bran fiber to advance the properties for the jerky.

Therefore, the objectives of this study were to evaluate the effects of various levels of added rice bran fiber (RBF) on the quality characteristics of semi-dried pork jerky (SDPJ) and identify the optimal level of RBF to manufacture of and an acceptable SDPJ.

\section{Materials and Methods}

\section{Extraction of dietary fiber from rice bran (RBF)}

Rice bran fiber (RBF) was extracted using the modified AOAC enzymatic-gravimetric method (AOAC, 2000). Rice bran (moisture, 12.12\%; protein, $12.32 \%$; fat, $20.31 \%$; ash, $8.73 \%$; digestible carbohydrates, $17.92 \%$; dietary fiber, $28.60 \%$; $\mathrm{pH}$, 6.85; lightness, 68.85; redness, 3.49; yellowness, 18.07) from a Japonica rice cultivar (Oriza sativa L.) was purchased from a market in Geochang, Gyeongsangnam-do, Korea, ground in a mill (SFM2000HS, Shinil Co. Ltd., Korea), and passed through a 25 mesh sieve. The rice bran was roasted to about $105^{\circ} \mathrm{C}$, and defatted with hexane ( $n$-hexane $95 \%)$ using a shaker (BS-11, Lab. Companion, Korea) overnight to remove lipids. The defatted rice bran was gelatinized with $0.6 \%$ termamyl (heat stable alpha-amylase) at $95^{\circ} \mathrm{C}$ for $1 \mathrm{~h}$ to remove starch, followed by filtration. The residue was then washed three times with four volumes of heated water $\left(100^{\circ} \mathrm{C}\right)$ and allowed to equilibrate to room temperature $\left(20^{\circ} \mathrm{C}, 6 \mathrm{~h}\right)$. The residue was then washed with $99.9 \%$ ethanol (preheated to $60^{\circ} \mathrm{C}$ ), followed by filtration. The residue was then dried $\left(55^{\circ} \mathrm{C}\right)$ overnight in an air oven and cooled. The RBF (moisture, 11.73\%; protein, $21.91 \%$; fat, $4.31 \%$; ash, $7.42 \%$; digestible carbohydrates, $1.38 \%$; dietary fiber, $53.25 \%$; $\mathrm{pH}, 7.07$; lightness, 66.10; redness, 4.73; yellowness, 16.06) was then placed in polyethylene bags, vacuum packaged using a vacuum packaging system (FJ-500XL, Fujee Tech, Seoul, Korea) and stored at $4^{\circ} \mathrm{C}$ until required for product manufacture.

\section{Meat and curing solution preparation}

Portions of M. biceps femoris, M. semitendinosus, and M. semimembranosus in fresh pork were purchased from a local processor at $48 \mathrm{~h}$ postmortem. The $\mathrm{pH}$ of the pork was $5.51 \pm 0.04$. All subcutaneous and intramuscular fat and visible connective tissue were removed from the fresh muscles. The fat contents of the trimmed pork were $5.12 \pm 0.12 \%$. Lean pork was ground through an $\emptyset-8 \mathrm{~mm}$ plate. The composition $(\mathrm{w} / \mathrm{w})$ of jerky curing solution was water $(10.0 \%)$, soy sauce $(9.0 \%)$, starch syrup $(3.2 \%)$, sugar $(2.0 \%)$, D-sorbitol $(5.5 \%)$, black pepper $(0.18 \%)$, ginger powder $(0.1 \%)$, garlic powder $(0.17 \%)$ onion powder $(0.17 \%)$, sodium nitrate $(0.005 \%)$ as a coupler, sodium citrate $(0.005 \%)$, potassium sorbate $(0.09 \%)$, sodium erythorbate $(0.03 \%)$, soup stock powder $(0.08 \%)$, meat stock $(0.4 \%)$, teriyaki seasoning $(0.1 \%)$, konjac $(0.15 \%)$ as a humectant and RBF $(0,1,2$, and $3 \%)$. Also, salt $(0.3 \%)$ and phosphate $(0.15 \%)$ were added to the binding meat.

\section{Preparation of semi-dried pork jerky (SDPJ)}

The semi-dried pork jerky (SDPJ) were produced according to the following traditional recipe (Choi et al., 2008a). The manufacturing process of SDPJ is shown in Fig. 1. The binding meat was added to $15 \%$ of the total meat weight. The binding meat was initially ground and emulsified with a silent cutter (Cutter, Hermann Scharfen $\mathrm{GmbH}$, Germany) for $1 \mathrm{~min}$. After adding salt and phosphate, the binding meat was cut for an additional 2 min. The SDPJ were divided into four equal portions. The first batch was used as a control without RBF and the other batches were supplemented with various levels $(1,2$, and $3 \%$ ) of RBF. Ground meat, binding meat, and RBF were then mixed for $10 \mathrm{~min}$. The ground meat and binding meat were cured by tumbling with curing solution and stuffed into cellulose casings $(\varnothing-20 \mathrm{~mm})$. Each preparation was cut to $15 \mathrm{~cm}$-lengths. SDPJ dried for $60 \mathrm{~min}$ at $55^{\circ} \mathrm{C}$ in a hot air drier (Enex-CO-600, Enex, Yongin, Korea) was removed from the casings, and jerky processing was carried out as follows: $55^{\circ} \mathrm{C}(180 \mathrm{~min}) \rightarrow 65^{\circ} \mathrm{C}$ $(180 \mathrm{~min}) \rightarrow 80^{\circ} \mathrm{C}(60 \mathrm{~min}) \rightarrow 25^{\circ} \mathrm{C}(30 \mathrm{~min})$.

\section{Proximate composition}

Compositional properties of the samples were performed using AOAC methods (2000). Moisture content 


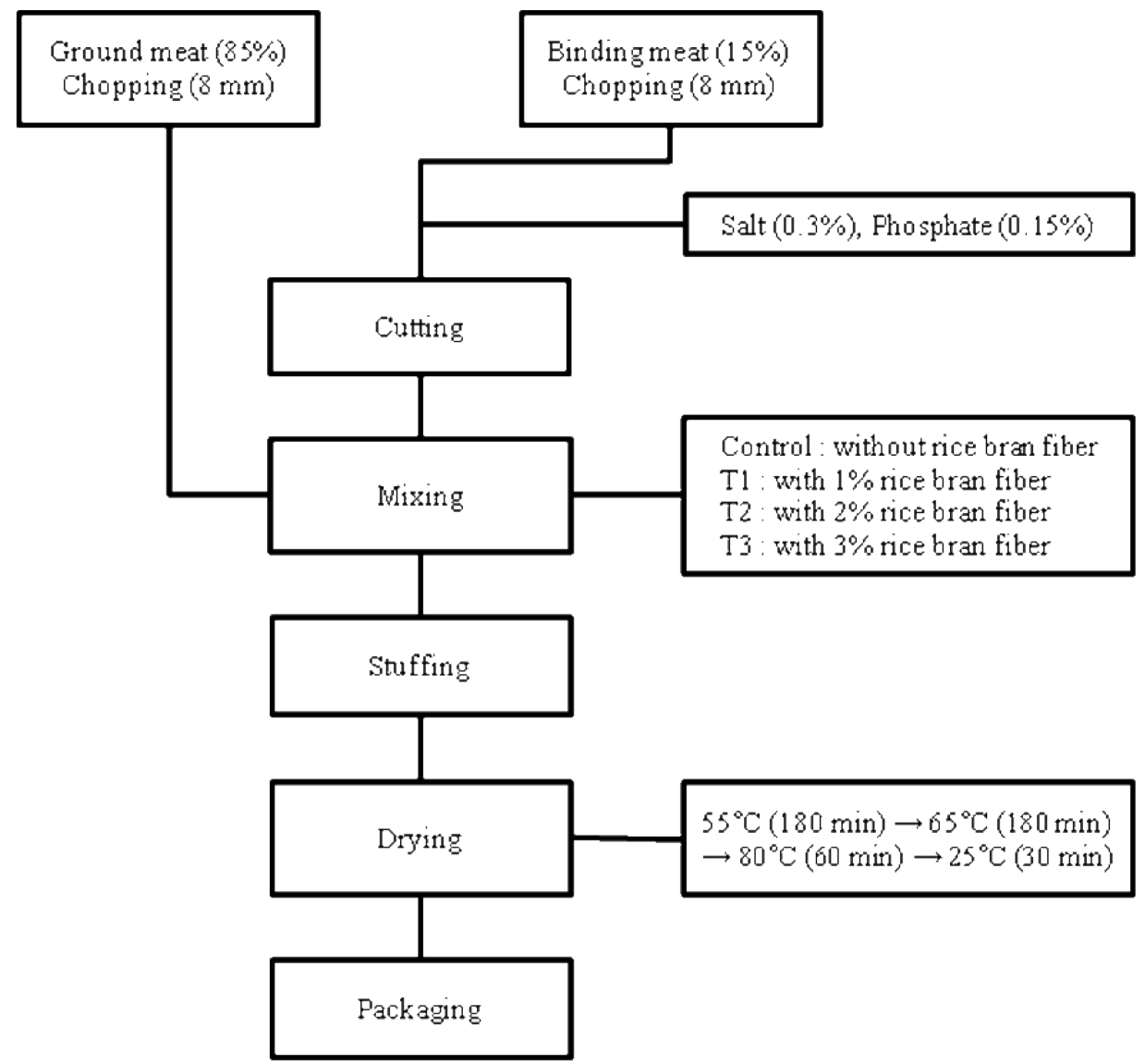

Fig. 1. Processing of SDPJ formulated with various levels of RBF.

(950.46B, oven air-drying method) was determined by weight loss after $12 \mathrm{~h}$ of drying at $105^{\circ} \mathrm{C}$ in a drying oven (SW-90D, Sang Woo Scienctific Co., Bucheon, Korea). Fat content (960.69, ether extractable component) was determined by Soxhlet method with a solvent extraction system (Soxtec ${ }^{\circledR}$ Avanti 2050 Auto System, Foss Tecator AB, Höganas, Sweden), and protein content (981.10) was determined by the Kjeldahl method with an automatic Kjeldahl nitrogen analyzer (Kjeltec ${ }^{\circledR} 2300$ Analyzer Unit, Foss Tecator AB, Höganas, Sweden). Ash content was determined according to AOAC method 923.153 (meffle furnace).

\section{Dietary fiber content}

The dietary fiber content was determined as described by Prosky et al. (1998). Samples were analyzed using heat stable alpa-amylase, protease, and amyloglucosidase (Sigma Chemical Co., St Louis, MO, USA) to remove starch proteins.

\section{Processing yields}

Processing yield was determined by calculating the weight differences of jerky before and after drying as follows:

$$
\begin{aligned}
& \text { Processing yield (\%) } \\
& =\frac{\text { jerky weight after drying }}{\text { cured meat weight before drying }} \times 100
\end{aligned}
$$

\section{pH}

The $\mathrm{pH}$ values of samples were measured in a homogenate prepared with $5 \mathrm{~g}$ of sample and distilled water (20 $\mathrm{mL}$ ) using a $\mathrm{pH}$ meter (Model 340, Mettler-Toledo $\mathrm{GmbH}$, Schwerzenbach, Switzerland). All determinations were performed in triplicate.

\section{Water activity}

Samples for measuring water activity were minced into pieces approximately $1 \mathrm{~mm} \times 1 \mathrm{~mm} \times 1 \mathrm{~mm}$ in size. The water activity of each sample was determined in duplicate with a hygrometer (BT-RS1, Rotronic AG., Bassersdorf, Switzerland).

\section{TBARS value}

Lipid oxidation was assessed in triplicate by the 2- 
thiobarbituric acid (TBA) method of Tarladgis et al. (1960) with minor modifications. A $10 \mathrm{~g}$ sample was blended with $50 \mathrm{~mL}$ distilled water for $2 \mathrm{~min}$ and then transferred to a distillation tube. The cup used for blending was washed with an additional $47.5 \mathrm{~mL}$ of distilled water, which was added to the same distillation flask with $2.5 \mathrm{~mL} 4 \mathrm{~N} \mathrm{HCl}$ and a few drops of an antifoam agent, silicone o/w (KMK-73, Shin-Etsu Silicone Co., Ltd., Seoul, Korea). The mixture was distilled and $50 \mathrm{~mL}$ distillate was collected. $5 \mathrm{~mL}$ of $0.02 \mathrm{M}$ 2-thiobarbituric acid in $90 \%$ acetic acid (TBA reagent) was added to a vial containing $5 \mathrm{~mL}$ of the distillate and mixed well. The vials were capped and heated in a boiling water bath for 30 min to develop the chromogen and cooled to room temperature. The absorbance was measured at $538 \mathrm{~nm}$ against a blank prepared with $5 \mathrm{~mL}$ distilled water and 5 $\mathrm{mL}$ TBA-reagent using a UV/VIS spectrophotometer (Optizen 2120 UV plus, Mecasys Co., Ltd., Daejeon, Korea). Thiobarbituric acid-reactive substances (TBARS) were calculated from a standard curve $(8-50 \mathrm{nmol})$ of malondialdehyde (MA) freshly prepared by acidification of TEP (1,1,3,3-tetraethoxy propane). Reagents were obtained from Sigma (UK). The TBA levels were calculated as $\mathrm{mg} \mathrm{MA} / \mathrm{kg}$ sample.

\section{Percent metmyoglobin}

Metmyoglobin concentration in SDPJ samples was determined using a modification of procedures by Kryzwicki (1979). Briefly, samples were blended with 5 volumes of cold $0.04 \mathrm{M}$ phosphate buffer at $\mathrm{pH} 6.8$ for $10 \mathrm{~s}$ in a homogenizer (Model AM-7, Nihonseiki Kaisha Ltd., Tokyo, Japan). After standing at $1^{\circ} \mathrm{C}$ for $24 \mathrm{~h}$, the mixtures were centrifuged at $3500 \times \mathrm{g}$ at $4^{\circ} \mathrm{C}$ for $30 \mathrm{~min}$. The supernatant was further clarified by filtration through Whatman No. 1 filter paper. The absorbance of filtrate was measured at 525, 572, and $700 \mathrm{~nm}$ using a spectrophotometer (Optizen III, Mecasys, Seoul, Korea). The percent metmyoglobin was calculated using the following formula:

$$
\begin{aligned}
& \text { Metmyoglobin }(\%) \\
& =\left[1.395-\left(\mathrm{A}_{572}-\mathrm{A}_{700}\right) /\left(\mathrm{A}_{525}-\mathrm{A}_{700}\right)\right] \times 100
\end{aligned}
$$

Where $\mathrm{A}_{\lambda}=$ Absorbance at $\lambda \mathrm{nm}$

\section{Shear force measurement}

Shear force values were determined with a WarnerBratzler shear attachment on a texture analyzer (TAXT2i, Stable Micro System Ltd., Surrey, UK). Test speeds were set at $2 \mathrm{~mm} / \mathrm{s}$. Data were collected and analyzed from the shear force values to obtain the maximum force required to shear through each sample and were then converted into $\mathrm{N}$.

\section{Sensory evaluation}

SDPJ samples were evaluated for color, flavor, juiciness, tenderness and overall acceptability. SDPJ samples prepared with various RBF levels were subjected to sensory evaluations. The samples were served to 12 experienced panel members. Each sample was coded with a randomly selected 3-digit number. All sensory evaluations were performed under fluorescent lighting. Panelists were instructed to cleanse their palates between samples using water. The color $(1=$ extremely undesirable, $10=$ extremely desirable), flavor $(1=$ extremely undesirable, $10=$ extremely desirable $)$, tenderness $(1=$ extremely tough, $10=$ extremely tender $)$, juiciness $(1=$ extremely dry, $10=$ extremely juicy $)$, and overall acceptability $(1=$ extremely undesirable, $10=$ extremely desirable) of the cooked samples were evaluated using a 10-point hedonic scale.

\section{Statistical analysis}

An analysis of variance was performed on all the variables measured using the general linear model (GLM) procedure of the SAS statistical package (SAS Institute) (2008). Duncan's multiple range test $(p<0.05)$ was used to determine differences between treatment means.

\section{Results and Discussion}

\section{Proximate composition of SDPJ}

The proximate compositions of SDPJ formulated with various RBF levels are shown in Table 1. The differences in moisture, protein, and ash content of each SDPJ formulation were statistically significant $(p<0.05)$. The moisture content of SDPJ supplemented with $2 \%$ RBF (T2) was significantly higher than the control $(p<0.05)$. These results agree with those reported by Choi et al. (2010), who found significantly increased moisture contents in meat batters with added dietary fiber since the addition of RBF increased the water holding capacity of meat batters. In addition, García et al. (2002) indicated that the moisture contents of dry fermented sausages supplemented with wheat, oat, and fruit fiber were higher than the control due to the high water retention of the fiber. In this study, the moisture content of jerky supplemented with RBF was higher than control without RBF. Similar results 
Table 1. Proximate composition of SDPJ with various levels of RBF ${ }^{1)}$

\begin{tabular}{lcccc}
\hline \hline Treatment ${ }^{2)}$ & Control & T1 & T2 & T3 \\
\hline Moisture (\%) & $32.18 \pm 0.72^{\mathrm{b}}$ & $34.78 \pm 1.29^{\mathrm{ab}}$ & $35.51 \pm 0.43^{\mathrm{a}}$ & $34.20 \pm 0.65^{\mathrm{ab}}$ \\
Fat (\%) & $19.99 \pm 1.51$ & $20.03 \pm 1.94$ & $20.18 \pm 1.89$ & $20.76 \pm 1.42$ \\
Protein (\%) & $39.77 \pm 0.53$ & $38.63 \pm 0.27$ & $37.36 \pm 0.39$ & $37.16 \pm 0.64$ \\
Ash (\%) & $4.38 \pm 0.08^{\mathrm{c}}$ & $4.44 \pm 0.08^{\mathrm{c}}$ & $4.63 \pm 0.11^{\mathrm{b}}$ & $5.05 \pm 0.09^{\mathrm{a}}$ \\
\hline
\end{tabular}

${ }^{1)}$ All values are mean \pm SD of three replicates.

${ }^{2)}$ Control, SDPJ without RBF, T1: SDPJ with $1 \%$ RBF, T2: SDPJ with $2 \%$ RBF, T3: SDPJ with 3\% RBF.

${ }^{\mathrm{a}-\mathrm{c}}$ Means within a row with different letters are significantly different $(p<0.05)$.

observed by Fernández-Ginés et al. (2004) when lemon albedo as a source of dietary fiber overly added to products the moisture content of bologna sausage decreased. The fat contents of SDPJ were not affected by various levels of RBF ( $p>0.05)$. Thebaudin et al. (1997) reported that dietary fiber added to meat products enhances fat retention. Piñero et al. (2008) reported that the fat retention of beef patties with added oat fiber was significantly higher than the control since the oat hydrocolloidal fiber creates a tridimensional matrix that holds the fat. The protein content was not significantly in the control and treatment with RBF. The ash content increased as the RBF level increased $(p<0.05)$, and was highest in jerky containing 3\% RBF (T3). These results agree with those reported by Serrano et al. (2007) and Choi et al. (2010), who indicated that ash content significantly increased due to the addition of dietary fiber to meat products.

\section{Processing yields of SDPJ}

The processing yields of SDPJ prepared with various levels of RBF are given in Fig. 2. The processing yields of SDPJ significantly increased as the level of RBF increased $(p<0.05)$. There are many studies indicating that dietary fiber can be added to meat products such as

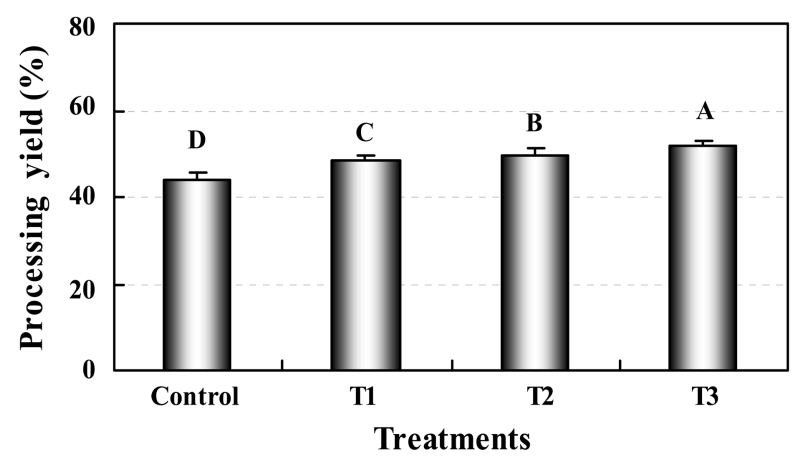

Fig. 2. Processing yields of SDPJ formulated with various levels of RBF. ${ }^{\mathrm{A}-\mathrm{D}}$ Means with different letters are significantly different $(p<0.05)$. Control, SDPJ without RBF; T1, SDPJ with $1 \%$ RBF; T2, SDPJ with $2 \%$ RBF; T3, SDPJ with $3 \%$ RBF. patties (Piñero et al., 2008), sausages (Fernández-Ginés et al., 2004), and batters (Choi et al., 2010) to increase the processing yield due to its water and fat binding properties. This effect was observed by Jiménez-Colmenero et al. (2003); as the proportion of walnut increased, the total loss of restructured beef decreased from $15.08 \%$ to $10.20 \%$. Kuo and Ockerman (1985) reported similar results with the dry yield of Chinese dried meat products increasing from $45 \%$ to $70 \%$, and Han et al. (2007) observed an increase from $47 \%$ to $50 \%$ in dry yield value which is in agreement with this study. Moreover, Thebaudin et al. (1997) reported that dietary fiber has water retention properties, and this property enhances water retention in meat products during cooking. So this may explain the increase in yield.

\section{pH and water activity of SDPJ}

$\mathrm{pH}$ is a fundamental factor affecting the physicochemical properties of meat products, since it influences freshness, water-holding capacity, binding ability, tenderness, color, and texture of meat (Choi et al., 2010). Table 2 presents the $\mathrm{pH}$ values of SDPJ prepared with difference levels of RBF. The $\mathrm{pH}$ values of jerky formulated with RBF ranged from 6.41 to 6.50 , with the control having the lowest $\mathrm{pH}$ of $6.29(p<0.05)$. As the addition of RBF increased, the $\mathrm{pH}$ value increased due to the basic $\mathrm{pH}$ of RBF. Similar results were obtained by Choi et al. (2008b) in that the addition of $\mathrm{RBF}$ increased the $\mathrm{pH}$ value of meat products in accordance with RBF alkalinity. In contrast to this result, Sarıçoban et al. (2008) reported that the $\mathrm{pH}$ value of meat emulsions made with lemon albedo is lower than the control, though this may be due to the presence of organic acids in albedo.

The water activity values of SDPJ are shown in Table 2. Among the control and treatments with RBF did not significant difference $(p>0.05)$. Choi et al. (2008a) reported similar results for the water activities of SDPJ samples prepared with various proportions of pork/beef and casings which ranged from 0.82-0.88. Also, Choi et al. (2007a) 
Table 2. Physicochemical properties of SDPJ with various levels of RBF ${ }^{1)}$

\begin{tabular}{lcccc}
\hline \hline Treatment ${ }^{2}$ & Control & T1 & T2 & T3 \\
\hline $\mathrm{pH}$ & $6.29 \pm 0.01^{\mathrm{c}}$ & $6.41 \pm 0.04^{\mathrm{b}}$ & $6.42 \pm 0.03^{\mathrm{b}}$ & $6.50 \pm 0.04^{\mathrm{a}}$ \\
Water activity & $0.80 \pm 0.02$ & $0.81 \pm 0.02$ & $0.82 \pm 0.02$ & $0.84 \pm 0.01$ \\
TBA (mg/kg) & $0.25 \pm 0.04^{\mathrm{b}}$ & $0.37 \pm 0.05^{\mathrm{a}}$ & $0.38 \pm 0.02^{\mathrm{a}}$ & $0.41 \pm 0.08^{\mathrm{a}}$ \\
Metmyoglobin (\%) & $89.78 \pm 1.34^{\mathrm{a}}$ & $88.69 \pm 0.70^{\mathrm{a}}$ & $87.08 \pm 1.05^{\mathrm{b}}$ & $84.60 \pm 1.57^{\mathrm{c}}$ \\
\hline
\end{tabular}

${ }^{1)}$ All values are mean \pm SD of three replicates.

${ }^{2)}$ Control, SDPJ without RBF; T1, SDPJ with 1\% RBF; T2, SDPJ with 2\% RBF; T3, SDPJ with 3\% RBF.

${ }^{\mathrm{a}-\mathrm{c}}$ Means within a row with different letters are significantly different $(p<0.05)$.

reported that the water activity of restructured jerky was affected by the packaging method and curing ingredients. In general, Water activity is important for determining microbial growth rates and is an important quality control characteristic, has a potent effect on the color, texture, and fat rancidity of jerky products (Choi et al., 2007a).

\section{TBA value and metmyoglobin of SDPJ}

The TBA (thiobarbituric acid) values of SDPJ formulated with various levels of RBF are given in Table 2. The TBA values increased in proportion to the RBF content, and all formulations with added RBF had TBA values significantly higher than the control $(p<0.05)$. These results may be due to the increased fat rancidity of rice bran (Choi et al., 2010), but there are no significantly difference among the treatments with RBF. According to Park et al. (2003), rice bran contains antioxidants such as vitamin B groups, vitamin E, and ggg-oryzanol. However, in this results, the addition of rice bran fiber was not related to the TBA values due to rice bran was passed through defatted process, the RBF holds approximately $4 \%$ fat contents. Also, Yang and Lee (2002) reported that the first stage TBA value of beef and pork jerky was in the range of $0.239-0.367 \mathrm{mg} / \mathrm{kg}$, which is similar to this study. TBA values reflect the aldehyde levels in meat products, which is an indication of fat rancidity (GuillénSans and Guzmán-Chozas, 1998). Thus, TBA values can be used to index the degree of freshness of meat products and are therefore widely used to measure lipid oxidation in meat products (Chen and Wailmaleongor-ek, 1981). Guillén-Sans and Guzmán-Chozas (1998) and Fernández et al. (1997) reported that the oxidation of lipids leading to rancidity is one of the most important changes during food processing. Lipid oxidation in muscle causes changes in the color, flavor, and texture of the meat product.

The percent metmyoglobin values of SDPJ formulated with various RBF levels are shown in Table 2 . The percent metmyoglobin values of jerky prepared with $2 \%$ and
$3 \%$ RBF were significantly lower than the control and $1 \% \operatorname{RBF}(p<0.05)$. It has been reported that the percent metmyoglobin of SDPJ prepared with various pork/beef levels and casings generally ranged from 85.56 to 89.07 (Choi et al., 2008a). The previous other study shows that the high percent of metmyoglobin in SDPJ was affected by extended cooking and curing times (Choi et al., 2008a). Bekhit et al. (2003) reported that the percent of metmyoglobin was positively correlated with TBA value in meat product, but in this study the percent of metmyoglobin decreased as the TBA value increased. In this study, as the addition of RBF increased, the proportion of meat to the proportion of total weight decreased, this may be caused the percent of metmyoglobin decreased. In general, myoglobin denaturation is affected by grinding and mixing (Govindarajan et al., 1997), processing temperature (Sherwin and Labuza, 2003), the addition of salt (Huffman et al., 1981) and lipid oxidation (Faustman and Cassens, 1990).

\section{Shear force values of SDPJ}

Texture in the jerky products has an important role in quality perception, and determines market attractiveness of this type of product (Konieczny et al., 2007). Shear force is the force needed to change the form of the food and is the most important characteristic in dehydrated foods. Fig. 3 shows the shear force values of SDPJ samples with various $\mathrm{RBF}$ levels. Jerky samples with $2 \%$ RBF (T2) and 3\% RBF (T3) had significantly lower values than the control $(p<0.05)$. These results agree with those of Thebaudin et al. (1997), who indicated that the hardness of the meat product were improved when dietary fiber was added to the formulation. An et al. (2010) reported that the hardness of semi-dry jerky decreased with the addition of kimchi fiber. According to García et al. (2002), the presence of fruit fiber decreases the hardness of sausage because the fruit fiber reduces the water loss thus lowering the hardness. In addition, shear force values can be affected by water activity, moisture content 


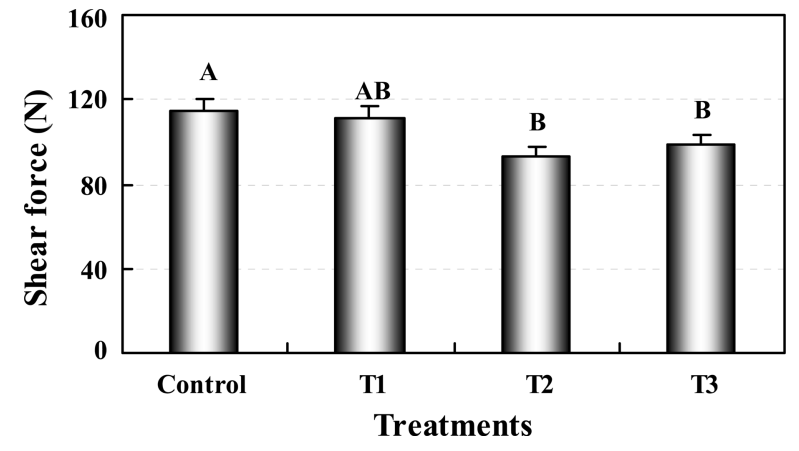

Fig. 3. Shear force of SDPJ formulated with various levels of RBF. ${ }^{\mathrm{A}, \mathrm{B}}$ Means with different letters are significantly different $(p<0.05)$. Control, SDPJ without RBF; T1, SDPJ with $1 \%$ RBF; T2, SDPJ with $2 \%$ RBF; T3, SDPJ with $3 \% \mathrm{RBF}$

and cooking yield (Choi et al., 2006, 2010). Also, Konieczny et al. (2007) reported that the moisture contents of jerky products have an important effect on textural properties.

\section{Sensory evaluation}

Results from the sensory evaluation of SDPJ prepared with various levels of RBF are presented in Table 3. Albright et al. (2003) reported that texture, color, and flavor are the most important sensory attributes of jerky products. The properties evaluated in this study were color, flavor, tenderness and juiciness. SDPJ prepared with $2 \%$ RBF (T2) received significantly higher color, tenderness, and juiciness scores than the control $(p<0.05)$, though there was no significant difference in flavor between the control jerky and jerky prepared with rice bran $(p>0.05)$. Especially, tenderness scores were presented similar results of shear force. SDPJ prepared with 2\% RBF (T2) received the highest overall acceptability score. Similar results were obtained by Choi et al. (2008b) for low-fat meat products containing RBF, and Yang et al. (2007) for pork sausages with added oatmeal and tofu. Also, sausages with added carrageenan had better sensory scores for juiciness and tenderness than control sausages (1992).
In summary, the results of the present study reveal that the properties of SDPJ are influenced by the addition of RBF. Specifically, when SDPJ was prepared with $2 \%$ RBF, we obtained a SDPJ of good quality with reduced metmyoglobin content (\%) and shear values, increased processing yield, and improved most sensory attributes, except for flavor, but increased TBA values. Thus, among addition levels of rice bran fiber, $2 \%$ can be acceptable content to improve the quality of SDPJ, but further study was required to reduce the rancidity induced by the addition of RBF.

\section{Acknowledgements}

This research was supported (808010-3-1-2) by the Ministry of Agriculture and Forestry (Republic of Korea). The authors were also partially supported by the Brain Korean 21 (BK 21) Project from Ministry of Education and Human Resources Development.

\section{References}

1. Albright, S. N., Kendall, P. A., Avens, J. S., and Sofos, J. N. (2003) Pretreatment effect on inactivation of Escherichia coli O157:H7 inoculated beef jerky. LWT-Food Sci. Technol. 36, 381-389.

2. An, K. I., Choi, J. H., Choi, Y. S., Han, D. J., Kim, H. Y., Lee, M. A., Kim, S. Y., Kim, T. H., and Kim, C. J. (2010) Effects of kimchi powder on quality characteristics of semi-dried pork jerky. Korean J. Food Sci. Ani. Resour. 30, 198-205.

3. AOAC (2000) Official methods of analysis of AOAC. 17th ed. Association of official analytical chemists, Washington DC.

4. Bekhit, A. E. D., Geesinkb, G. H., Iliana, M. A., Mortona, J. D., and Bickerstaffea, R. (2003) The effects of natural antioxidants on oxidative processes and metmyoglobin reducing activity in beef patties. Food Chem. 81, 175-187.

5. Chen, T. C. and Wailmaleongor-ek, C. (1981) Effect of pH on TBA values of ground raw poultry meat. J. Food Sci. 46, 1946-1947.

6. Choi, J. H., Jeong, J. Y., Choi, Y. S., Han, D. J., Kim, H. Y.,

Table 3. Sensory properties of SDPJ formulated with various levels of RBF ${ }^{1)}$

\begin{tabular}{lllll}
\hline \hline \multicolumn{1}{c}{ Treatment $^{2}$} & Control & \multicolumn{1}{c}{ T1 } & T2 & T3 \\
\hline Color & $7.88 \pm 0.64^{\mathrm{b}}$ & $7.50 \pm 0.53^{\mathrm{b}}$ & $8.63 \pm 0.74^{\mathrm{a}}$ & $8.13 \pm 0.64^{\mathrm{ab}}$ \\
Flavor & $8.25 \pm 0.46$ & $8.13 \pm 0.64$ & $8.38 \pm 0.74$ & $7.88 \pm 0.64$ \\
Tenderness & $7.38 \pm 0.52^{\mathrm{b}}$ & $7.88 \pm 0.64^{\mathrm{ab}}$ & $8.13 \pm 0.64^{\mathrm{a}}$ & $7.38 \pm 0.52^{\mathrm{b}}$ \\
Juiciness & $7.13 \pm 0.35^{\mathrm{c}}$ & $7.63 \pm 0.52^{\mathrm{b}}$ & $8.00 \pm 0.53^{\mathrm{a}}$ & $7.38 \pm 0.52^{\mathrm{bc}}$ \\
Overall acceptability $^{\mathrm{b}}$ & $7.88 \pm 0.35^{\mathrm{b}}$ & $8.00 \pm 0.53^{\mathrm{ab}}$ & $8.50 \pm 0.53^{\mathrm{a}}$ & $7.63 \pm 0.52^{\mathrm{b}}$ \\
\hline
\end{tabular}

${ }^{1)}$ All values are mean $\pm \mathrm{SD}$ of three replicates.

${ }^{2)}$ Control, SDPJ without RBF; T1, SDPJ with $1 \%$ RBF; T2, SDPJ with $2 \%$ RBF; T3, SDPJ with $3 \%$ RBF.

${ }^{\mathrm{a}-\mathrm{c}}$ Means within a row with different letters are significantly different $(p<0.05)$. 
Lee, M. A., Lee, E. S., Paik, H. D., and Kim, C. J. (2006) The effects of marination condition on quality characteristics of cured pork meat and sensory properties of pork jerky. Korean J. Food Sci. Ani. Resour. 26, 229-235.

7. Choi, J. H., Jeong, J. Y., Han, D. J., Choi, Y. S., Kim, H. Y., Lee, M. A., Lee, E. S., Paik, H. D., and Kim, C. J. (2008a) Effects of pork/beef levels and various casings on quality properties of semi-dried jerky. Meat Sci. 71, 278-286.

8. Choi, Y. S., Choi, J. H., Han, D. J., Kim, H. Y., Lee, M. A., Jeong, J. Y., Chung, H. J., and Kim, C. J. (2010) Effects of replacing pork back fat with vegetable oils and rice bran fiber on quality of reduced-fat frankfurters. Meat Sci. 84, 557-563.

9. Choi, Y. S., Choi, J. H., Han, D. J., Kim, H. Y., Lee, M. A., Kim H. W., Jeong, J. Y., and Kim, C. J. (2009) Characteristics of low-fat meat emulsion systems with pork fat replaced by vegetable oils and rice bran fiber. Meat Sci. 82, 266-271.

10. Choi, Y. S., Choi, J. H., Han, D. J., Kim, H. Y., Lee, M. A., Lee, E. S., Jeong, J. Y., Paik, H. D., and Kim, C. J. (2008b) Effects of rice bran fiber on quality of low-fat Tteckgalbi. Food Sci. Biotechnol. 17, 959-964.

11. Choi, Y. S., Jeong, J. Y., Choi, J. H., Han, D. J., Kim, H. Y., Lee, M. A., Paik, H. D., and Kim, C. J. (2007a) Effect of packaging methods on the quality properties of stick type restructured jerky. Korean J. Food Sci. Ani. Resour. 27, 290298.

12. Choi, Y. S., Choi, J. H., Han, D. J., Kim, H. Y., Lee, M. A., Jeong, J. Y., Chung, H. J., and Kim, C. J. (2010) Effects of replacing pork back fat with vegetable oils and rice bran fiber on the quality of reduced-fat frankfurters. Meat Sci. 84, 557563.

13. Chotimarkorn, C. and Silalai, N. (2008) Oxidative stability of fried dough from rice flour containing rice bran powder during storage. LWT - Food Sci. Technol. 41, 561-568.

14. Cofrades, S., Guerra, M. A., Carballo, J., Fernandez-Martin, F., and Colmenero, F. J. (2000) Plasma protein and soy fiber content effect on bologna sausage properties as influenced by fat level. J. Food Sci. 65, 281-287.

15. Faustman, C. and Cassens, R. G. (1990) The biochemical basis for discoloration in fresh meat: a review. J. Muscle Foods 1, 217-243.

16. Fernández-Ginés, J. M., Fernandez-López, J., Sayas-Barberá, E., Sendra, E., and Pérez-Álvarez, J. A. (2004) Lemon albedo as a new source of dietary fiber: Application to bologna sausages. Meat Sci. 67, 7-13.

17. Fernández-López, J., Sendra, E., Sayas-Barberá, E., Navarro, C., and Pérez-Alvarez, J. A. (2008) Physico-chemical and microbiological profiles of "salchichón" (Spanish dry-fermented sausage) enriched with orange fiber. Meat Sci. 80, 410-417.

18. Fernández, J., Pérez-Álvarez, J. A., and Fernández-López, J. A. (1997) Thiobarbituric acid test for monitoring lipid oxidation in meat. Food Chem. 59, 345-353.

19. García, M. L., Dominguez, R., Galvez, M. D., Casas, C., and Selgas, M. D. (2002) Utilization of cereal and fruit fibers in low fat dry fermented sausages. Meat Sci. 60, 227-236.

20. Govindarajan, S., Hultin, H. O., and Kotula, A. W. (1997)
Myoglobin oxidation in ground beef: Mechanistic studies. $J$. Food Sci. 42, 571-577.

21. Guillén-Sans, R. and Guzmán-Chozas, M. (1998) The thiobarbituric acid (TBA) reaction in foods: A review. CRFSN 38, 315-330

22. Han, D. J., Jeong, J. Y., Choi, J. H., Choi, Y. S., Kim, H. Y., Lee, M. A., Lee, E. S., Paik, H. D., and Kim, C. J. (2007) Effects of drying conditions on quality properties of pork jerky. Korean J. Food Sci. Ani. Resour. 27, 29-34.

23. Huang, S. C., Shiau, C. Y., Liu, T. E., Chu, C. L., and Hwang, D. F. (2005) Effects of rice bran on sensory and physicchemical properties of emulsified pork meatballs. Meat Sci. 70, 613-619.

24. Huffman, D. L., Ly, A. M., and Cordray, J. C. (1981) Effect of salt concentration on quality of restructured pork chops. $J$. Food Sci. 46, 1563-1565.

25. Jiménez, C. F., Serrano, A., Ayo, J., Solas, M. T., Cofrades, S., and Carballo, J. (2003) Physicochemical and sensory characteristics of restructured beef steak with added walnuts. Meat Sci. 65, 1391-1397.

26. Kim, I. S., Jin, S. K., Park, K. H., Kim, D. H., Hah, K. H., Park, S. T., Kwuak, K. R., Park, J. K., and Kang, Y. S. (2006) Changes in quality characteristics of venison jerky manufactured under different dry time during storage. Korean $J$. Food Sci. Ani. Resour. 26, 166-174.

27. Kim, K. M., Yu, K. W., Kang, D. H., Koh, J. H., Hong, B. S., and Suh, H. J. (2001) Anti-stress and anti-fatigue effects of fermented rice bran. Biosci. Biotechnol. Biochem. 65, 22942296.

28. Konieczny, P., Stangierski, J., and Kijowski, J. (2007) Physical and chemical characteristics and acceptability of home style beef jerky. Meat Sci. 76, 253-257.

29. Krzywicki, K. (1979) Assessment of relative content of myoglobin, oxymyoglobin and metmyoglobin at the surface of beef. Meat Sci. 3, 1-10.

30. Kuo, J. C. and Ockerman, H. W. (1985) Effect of salt, sugar and storage time on microbiological, chemical and sensory properties of Chineses style dried pork. J. Food Sci. 50, 1384-1387.

31. Lee, S. W., Lee, B. S., Cha, W. S., Park, J. H., Oh, S. L., Cho, Y. J., Kim, J. K., Hong, J. H., and Lee, W. Y. (2004) Diffusion of salt and drying characteristics of beef jerky. Korean $J$. Food Preser. 11, 508-515.

32. Piñero, M. P., Parra, K., Huerta-Leidenz, N., Arenas de Moreno, L., Ferrer, M., Araujo, S., and Barboza, Y. (2008) Effect of oat's soluble fibre ( $\beta$-glucan) as a fat replacer on physical, chemical, microbiological and sensory properties of low-fat beef patties. Meat Sci. 80, 675-680.

33. Prosky, K., Asp, L. G., Schweizer, T. F., Devries, J. W., and Furda, I. (1998) Determination of insoluble, soluble, and dietary fiber in foods and food products: in the laboratory study. J. AOAC 71, 1017-1023.

34. Sarıçoban, C., Özalp, B., Yılmaz, M. T., Özen, G., Karakaya, M., and Akbulut, M. (2008) Characteristics of meat emulsion systems as influenced by different levels of lemon albedo. Meat Sci. 80, 599-606. 
35. SAS (2008) SAS/STAT Software. Release 9.2, SAS Institute Inc., Cary, NC, USA.

36. Serrano, A., Librelotto, J., Cofrades, S., Sánchez-Muniz, F. J., and Jiménez-Colmenero, F. (2007) Composition and physicochemical characteristics of restructured beef steaks containing walnuts as affected by cooking method. Meat Sci. 77, 304-313.

37. Sherwin, C. P. and Labuza, T. P. (2003) Role of moisture in maillard browning reaction rate in intermediate moisture foods: comparing solvent phase and matrix properties. $J$. Food Sci. 68, 588-593.

38. Sudha, M. L., Vetrimani, R., and Leelavathi, K. (2007) Influence of fibre form different cereals on the rheological characteristics of wheat flour dough and on biscuit quality. Food Chem. 100, 1365-1370.

39. Tarladgis, B. G., Watts, B. M., Younathan, M. T., and Dugan, L. (1960) A distillation method for the quantitative determination of malonaldehyde in rancid foods. J. Am. Oil Chem. Soc. 37, 44-48.

40. Thebaudin, J. Y., Lefebvre, A. C., Harrington, M., and Bourgeois, C. M. (1997) Dietary fibres: Nutritional and techno- logical interest. Trends Food Sci. Technol. 8, 41-48.

41. Yang, C. Y. (2006) Physicochemical properties of chicken jerky with pear, pineapple and kiwi extracts. Korean $J$. Culin. Res. 12, 237-250.

42. Yang, C. Y. and Lee, S. H. (2002) A evaluation of quality of the marketing jerky in domestic (1. Investigation of outward appearance, food additives, nutrient content and sanitary state). J. Food Nutr. 15, 197-202.

43. Yang, H. S., Choi, S. G., Jeon, J. T., Park, G. B., and Joo, S. T. (2007) Textural and sensory properties of low fat pork sausages with added hydrated oatmeal and tofu as texture-modifying agents. Meat Sci. 75, 283-289.

44. Yilmaz, I. (2005) Physicochemical and sensory characteristics of low fat meatballs with added wheat bran. J. Food Eng. 69, 369-373.

45. Yilmaz, I. and Daglioglu, O. (2003) The effect of replacing fat with oat bran on fatty acid composition and physicochemical properties of meatballs. Meat Sci. 65, 819-823.

(Received 2010.9.18/Revised 1st 2010.12.1, 2nd 2010.12.3/ Accepted 2010.12.6) 